\title{
Assessment of Cutting Area Temperature to the Face Milling using Several Cooling Methods
}

Domnita Florina Fratila (RO) domnita.fratila@tcm.utcluj.ro

\section{BIOGRAPHICAL NOTES}

Domnita Fratila, Assoc.prof. Dr. Eng. (born in 1972) is an associated professor at the Technical University of Cluj-Napoca, Machine Building Faculty, Department of Manufacturing Engineering, Romania. She graduated at the Technical University of Cluj-Napoca, Machine Building Faculty, in 1996. Her professional orientation is focused on the manufacturing technologies, environment friendly techniques, eco-design, as well as microfabrication and micro-assembly. She is a member of the "Young Researches' and Scientists' Committee" in the framework of the "DAAAM International Association" and also member of the „Academic Association for Manufacturing Engineering."

\section{KEY WORDS}

Cooling Effect, Near Dry Machining, Face Milling, Dry Cutting

\section{ABSTRACT}

This paper analyzes the temperature variations in the cutting zone under flood cooling (FC), near dry machining (NDM) and dry cutting (DC) conditions. The research compares the dual effects of air-oil mixture in near-dry machining with the cooling effect to dry cutting and flood cooling in terms of the reduction of cutting temperature through the cooling effect, as well as the reduction of heat generation through the lubricating effect to face milling.

\section{INTRODUCTION}

Nowadays in the competition context manufacture no costs related to manufacturing processes can be ignored. When machining operations are performed, one of them is the cost related to use, maintenance and disposal of cutting fluids. Is it known the non-value added costs associated with flood coolants - parts cleaning, frequent floor cleaning, coolant additives such as biocides, chip cleaning, etc.

The metal machining companies are currently under increasing pressure of competition, environmental regulation, and supply chain demand for improved environmental performance as presenred in [6], [7], [10]. Conventional production knowledge has three levels consisting on: idea (design of new products), CAD (Computer Aided Design) and CAM (Computer Aided Manufacturing). As an alternative, the sustainable production put all these components on the same level defining the sustainable product based on sustainable principles as presented in Fig.1.

The environmentally friendly production techniques and the rapid growth of cutting fluid disposal costs have justified the demand for an alternative to machining processes using fluids. Thus, dry machining (DM) and Minimum Quantity Lubricant (MQL) machining have become the focus of attention of researchers and technicians in the field of machining as an alternative to traditional fluids as shown in [2], [4]. The 
most logical measure that could be considered to eliminate the cutting fluids from cutting processes is DM. To DM no cutting fluid is used, it means that there is more friction and adhesion between work piece and tool, and at the same time the thermal load of tool and work piece are greater. With NDM, also known as Minimal Quantity Lubrication, there are no flood coolants. Just a small amount of sprayed cutting fluid is applied directly to the cutting interface. Typical fluid consumption is on the order of $50-100 \mathrm{ml} /$ hour per nozzle and the chips are almost dry, having about $0,2 \%$ oil con- tent. In conventional machining the cutting fluids are needed (cooling lubrication fluids - CLF and cleaning emulsion-CE). Compared the environmentfriendly techniques have some potential benefits like: Sustainable machining through lower flow rates of CLF, providing better cooling and lubrication mechanisms;

Decreasing the cutting tool-chip contact length, resulting in lower cutting forces and lower tool wear;

Extension of machining parameters operational range, resulting in increased process productivity.

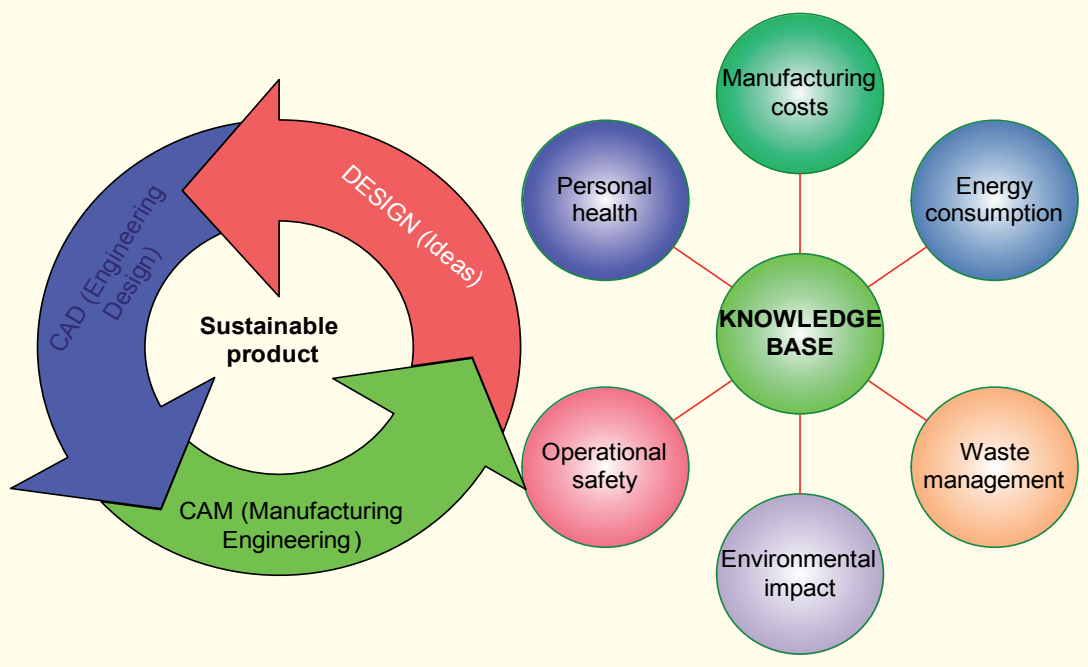

Fig. 1 Components of sustainable production

In the MQL the media feed in the cutting area in small quantities (as mentioned above) is generally the oil, but in some application the emulsion and water are used. MQL or NDM is the use of a minimal amount of cutting fluid mixed with air as an aerosol to provide controlled lubrication and reduce friction at the cutting-edge zone.

The transportation medium is usually air or the droplets are formed and feed to the cutting zone in the way of aerosol spray in the case of the airless system. Although some MQL-technology suppliers claim that any cutting fluid can be used with the technique, most shops use highly refined vegetable oil or ester oil.

These high-performance oils have excellent lubricity and natural dissolving properties, and they are environmentally friendly [5], [8]. With the increasing trends in the achieving sustainable machining, dry and near-dry techniques are emerging as viable and more sustainable alternatives to flood cooling in the machining processes.

Principally, every cutting and non-cutting process is convertible from closed circuit cooling with coolant lubricant to dry machining or minimal quantity lubrication. Due to the techniques flexibility, there are suitable individual solutions for a wide variety of manufacturing processes. MQL is used in almost every form of mechanical metal removal processes: sawing, turning, milling, high speed milling, boring, deep drilling, tapping, broaching, drill finishing with single and multiple edge cutting tools, and having still limited use in grinding $[1,3,8,9]$.

\section{Cooling Effect By NDM}

NDM by meaning the use of MQL and DM applications are growing continuously due to the following reasons: High costs of cutting fluids, in the range of $8-20 \%$ of manufacturing cost; 
Personal health, work safety, waste disposal, chip recycling;

- Progressive innovation in development of cutting tools involving advanced solutions.

NDM refers to the condition of applying cutting fluid at relatively low flow rates, as opposed to the conventional way of using either a large quantity, typically of about $10 \mathrm{l} / \mathrm{min}$, as in wet machining; or no fluid at all, as in dry machining. One main expectation of applying fluids is to control the cutting temperature, which is an important parameter for tool life and part dimensional accuracy in machining processes. In this context, it is of interest, the study of cutting temperature variation corresponding to the NDM and lubrication.

\subsection{NDM influencing variables}

The experiments planning aims the understanding of the NDM operations in the terms of major machining performance (cutting forces, surface roughness, surface accuracy) under the range of tool geometry, tool material, work piece material, cutting conditions, chips forms as shown in Fig. 2. There are several variables influencing the environment-friendly machining. These are presented in Fig. 3. By experimental research, the temperature variations have been determined in the cutting area under flood cooling (FC), near dry cooling and DC conditions.

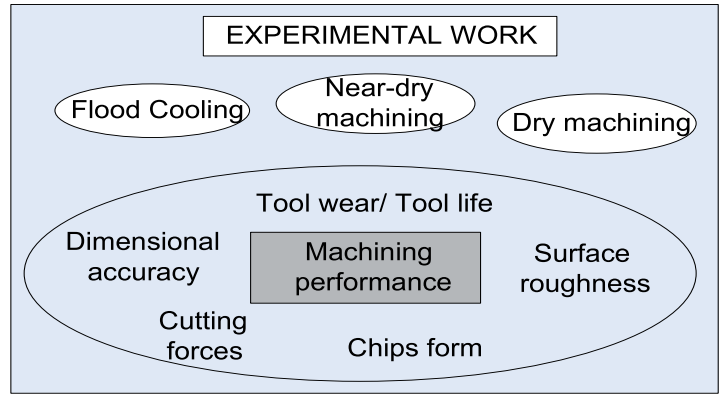

Fig. 2 General experiments planning

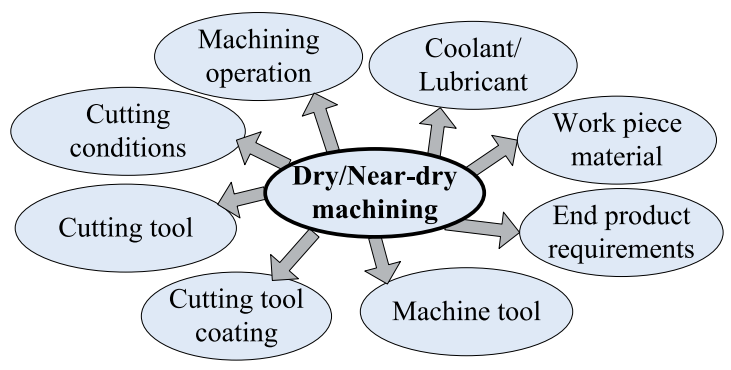

Fig. 3 Variables influencing DM and NDM
The research compares the dual effects of air-oil mixture in NDM, DC and FC in terms of the reduction of cutting temperature through the cooling effect, as well as the reduction of heat generation through the lubricating effect.

\subsection{Experimental setup}

Experiments have been performed on the HAAS TM-1CNC Milling machine. The experiment setup is schematically presented in Fig. 4. The variable process parameters were considered: coolant flow rate $Q[\mathrm{ml} / \mathrm{min}]$, cutting speed $v_{\mathrm{c}}[\mathrm{m} / \mathrm{min}]$, cutting depth $a_{\mathrm{p}}[\mathrm{mm}]$. The experiments have been planned as presented in Tab. 1. Emulsion 15\% and vegetable oil (raps oil) have been used as cutting fluids for FC- respectively MQL milling. The cutting fluid flow rate of $0 \mathrm{ml} / \mathrm{min}$ correspods to the dry machining.

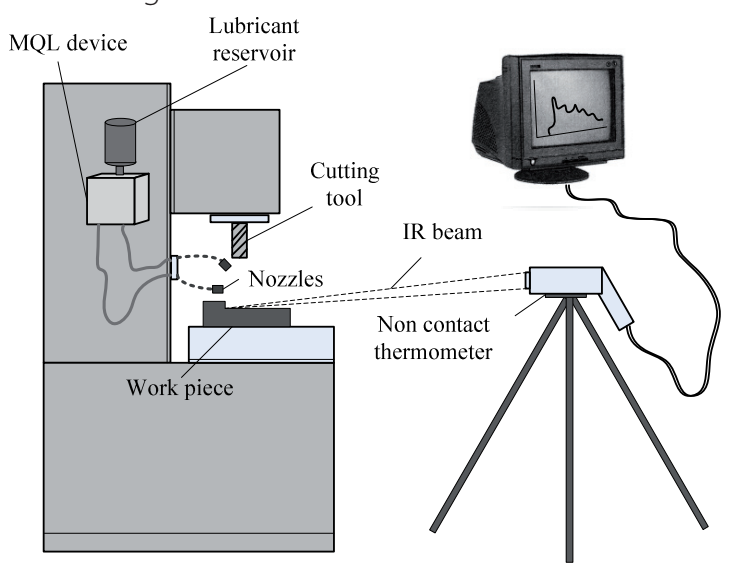

Fig. 4 Experimental setup

The first of the recorded parameters was the cutting area temperatures. In this sense it was used an non contact infrared thermometers XTempLS, that allow to appoint the cutting temperature in a range of $-35^{\circ} \mathrm{C}$ to $900^{\circ} \mathrm{C}$. The device has a temperature resolution of $0,1^{\circ} \mathrm{C}$ and the IR accuracy $\pm 0,75^{\circ} \mathrm{C}$. The recording interval, equal with diagram resolution, has been set to $20 \mathrm{msec}$.

For comparison purpose, the other checked output parameter of the face milling process was the power consumption, directly indicated on the CNC milling machine display.

\section{Results and Disscussions}

The results of experiments are summarized in the Tab. 1 too (last column). Concerning the power consumption the results show a $25 \%$ usage of tool 
machine power capacity in case of DC and $15 \%$ to MQL and FC. The temperature ongoing in each case of the above mentioned parameters variation was recorded using the appropriate device software OptrisConnect.

Three kind of temperatures were simultaneous measured: object (cutting area) temperature, internal temperature, and the external one. Some of these diagrams are shown in the Figs. 5, 6, 7. The cooling effect depends obviously of the cooling technique. For the same cooling lubrication method, the coolant flow rate do not have a significant influence on the temperatures developed in the cutting zone. FC provides a high stability of milling process by keeping constant the temperature in the cutting zone.

\begin{tabular}{|c|c|c|c|c|c|}
\hline \multirow{2}{*}{$\begin{array}{l}\text { Cutting speed } \\
{[\mathrm{m} / \mathrm{min}]}\end{array}$} & \multirow{2}{*}{$\begin{array}{l}\text { Cutting depth } \\
\text { [mm] }\end{array}$} & \multirow{2}{*}{$\begin{array}{l}\text { Coolant flow rate } \\
{[\mathrm{ml} / \mathrm{min}]}\end{array}$} & \multicolumn{3}{|c|}{ Maximal temperature $\left[{ }^{\circ} \mathrm{C}\right]$} \\
\hline & & & Obj & Ext & Int \\
\hline 150 & 2 & 0 & 86,1 & 22,2 & 25,2 \\
\hline 150 & 2,5 & 25 & 42,8 & 22,6 & 25 \\
\hline 200 & 2 & 25 & 48 & 22,1 & 24,9 \\
\hline 200 & 2,5 & 50 & 49,7 & 22,3 & 25,8 \\
\hline 250 & 2 & 0 & 123 & 21 & 26 \\
\hline 250 & 2,5 & 50 & 54,3 & 25 & 21,8 \\
\hline 150 & 2,5 & 1000 & 20,2 & 24,2 & 22,3 \\
\hline 200 & 2,5 & 1000 & 21,4 & 24,8 & 22,8 \\
\hline 250 & 2,5 & 1000 & 22,4 & 22,4 & 21,6 \\
\hline
\end{tabular}

Fig. 1 Components of sustainable production

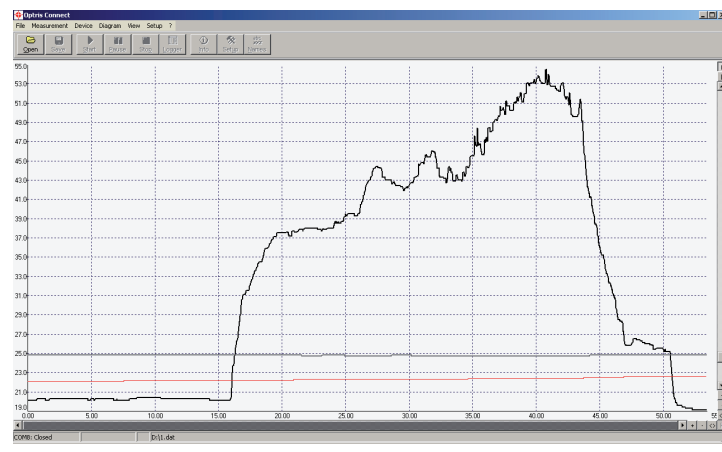

Fig. 5 Cutting area temperature to MQL milling ( $V C=250$ $\mathrm{m} / \mathrm{min}, a p=2.5 \mathrm{~mm}, \mathrm{Q}=50 \mathrm{~m} / \mathrm{min}$ )

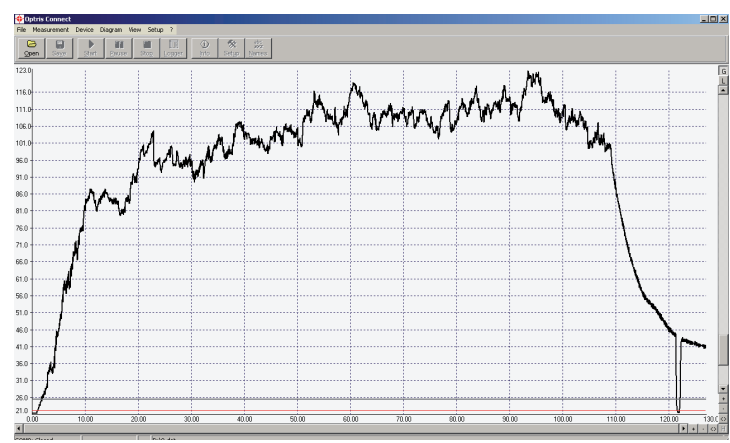

Fig. 6 Cutting area temperature to DC milling ( $\mathrm{VC}=250 \mathrm{~m}$ ) $\min , a p=2.5 \mathrm{~mm}, \mathrm{Q}=0 \mathrm{~m} / \mathrm{min}$ )

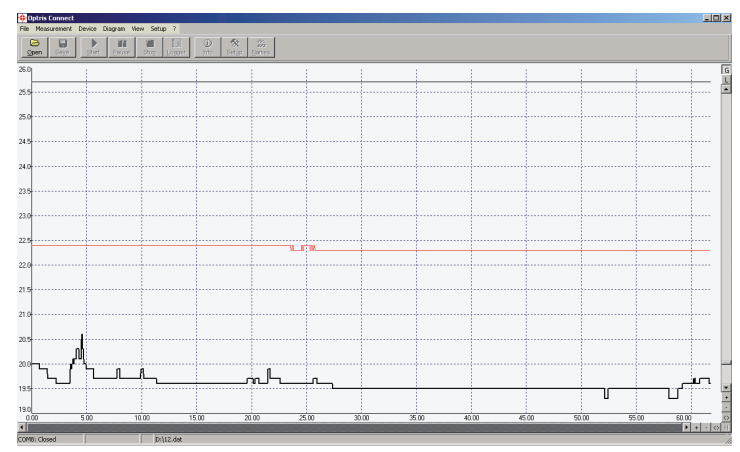

Fig. 7 Cutting area temperature to $F C$ milling ( $\mathrm{V} c=150 \mathrm{~m} /$ $\min , a p=2.5 \mathrm{~mm}, Q=1 \mathrm{l} / \mathrm{min}$ )

\section{Conclusions}

The evaluation of the environment-friendly techniqies was undertaken to understand the likely impacts of theis use on sustainability performance measures. The results are more than an experimental method for supporting design of technology but also an instrument for supporting decisionmaking in the case of gear milling. This reseach supports technology policy and encourages the adoption and the application of NDM in industry. 


\section{References}

[1] Brockhoff T., Walter, A., Fluid minimization in cutting and grinding. Journal of Abrasive Engineering Society, Oct-Nov 1998, Butler, Pa

[2] Dunlap C., Should you Try Dry? Cutting Tool Engineering, vol. 49, no.1, 1997, p. 22-33

[3] Kelly J.F., Cotterell M.G., Minimal lubrication machining of aluminum alloys. Journal of Material Processing Technology, no.12, 2002, Little Island, Cork, Ireland

[4] Machado A.R., Diniz, A.E., Advantages and disadvantages of the use of the cutting fluids. Machining Congress, São Paulo, Brazil, 2000

[5] Marksberry PW, Jawahir IS. A comprehensive tool-wear/tool-life performance model in the evaluation of NDM for sustainable manufacturing. International Journal of Machine Tools and Manufacture, vol. 48, no 7-8, 2008, p. 878886

[6] Pusavec F, Krajnik P, and Kopac J. Transition to sustainable production - Part I: application on machinig technologies. Journal of Cleaner Production, vol. 18, no. 2, 2008, p.174-184

[7] Pusavec F, Kramar D, et al., Transitioning to sustainable production - part II: evaluation of sustainable machining technologies. Journal of Cleaner Production. In Press, DOI:10.1016/j. jclepro.2010.01.015

[8] Rahman M., Kumar A.S., Salam MU, Experimental evaluation on effect of minimal quantity lubricant in milling. International Journal of Machine Tools \& Manufacture, no. 42, 2002, p. 539-547

[9] Weinert K, Inasaki I, et al. Dry machining and minimum quantity lubrication. CIRP AnnalsManufacturing Technology, vol. 53, no. 3, 2004, p. 511-537

[10] Westkämper E, et al. Life Cycle management and assessment: approaches and visions towards sustainable manufacturing. CIRP Annals - Manufacturing Technology, vol. 49, no. 2, p. 501-502

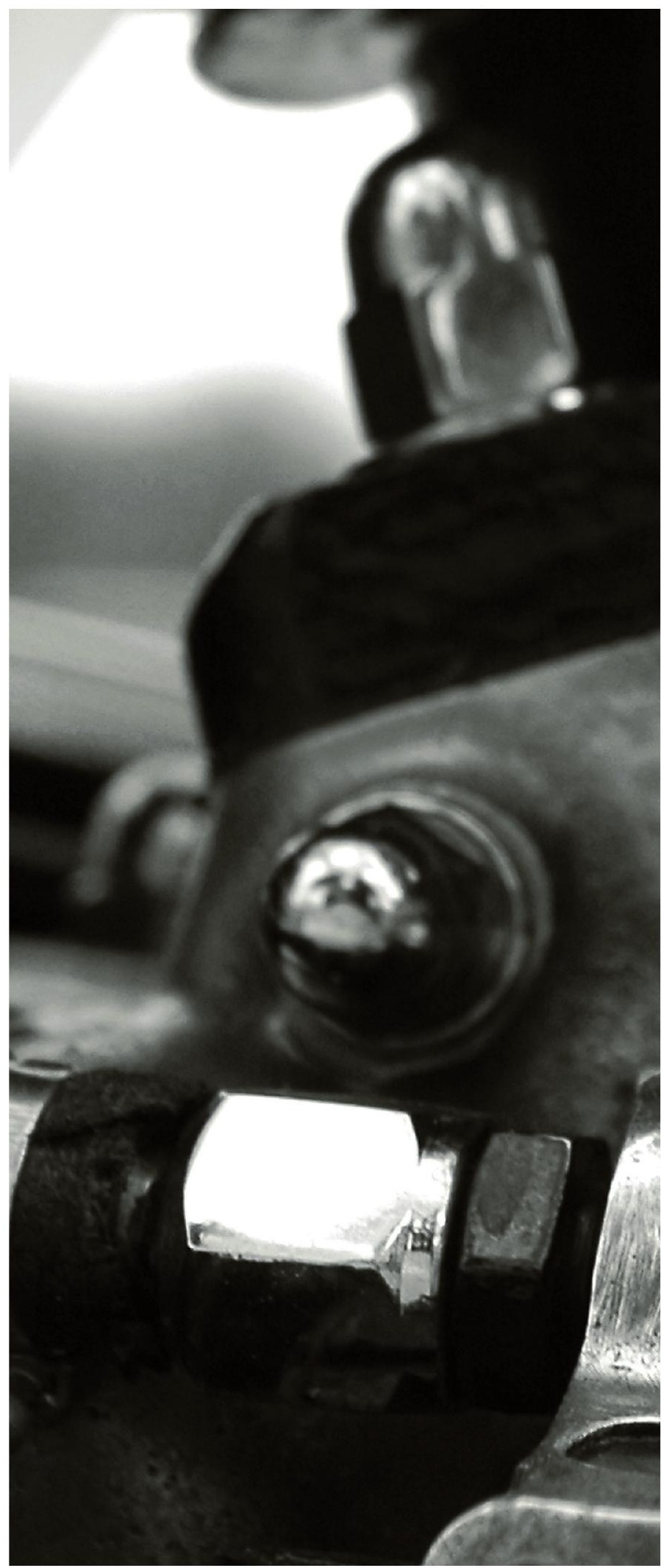


Acta Mechanica Slovaca

Journal published by Faculty of Mechanical Engineering - Technical University of Košice
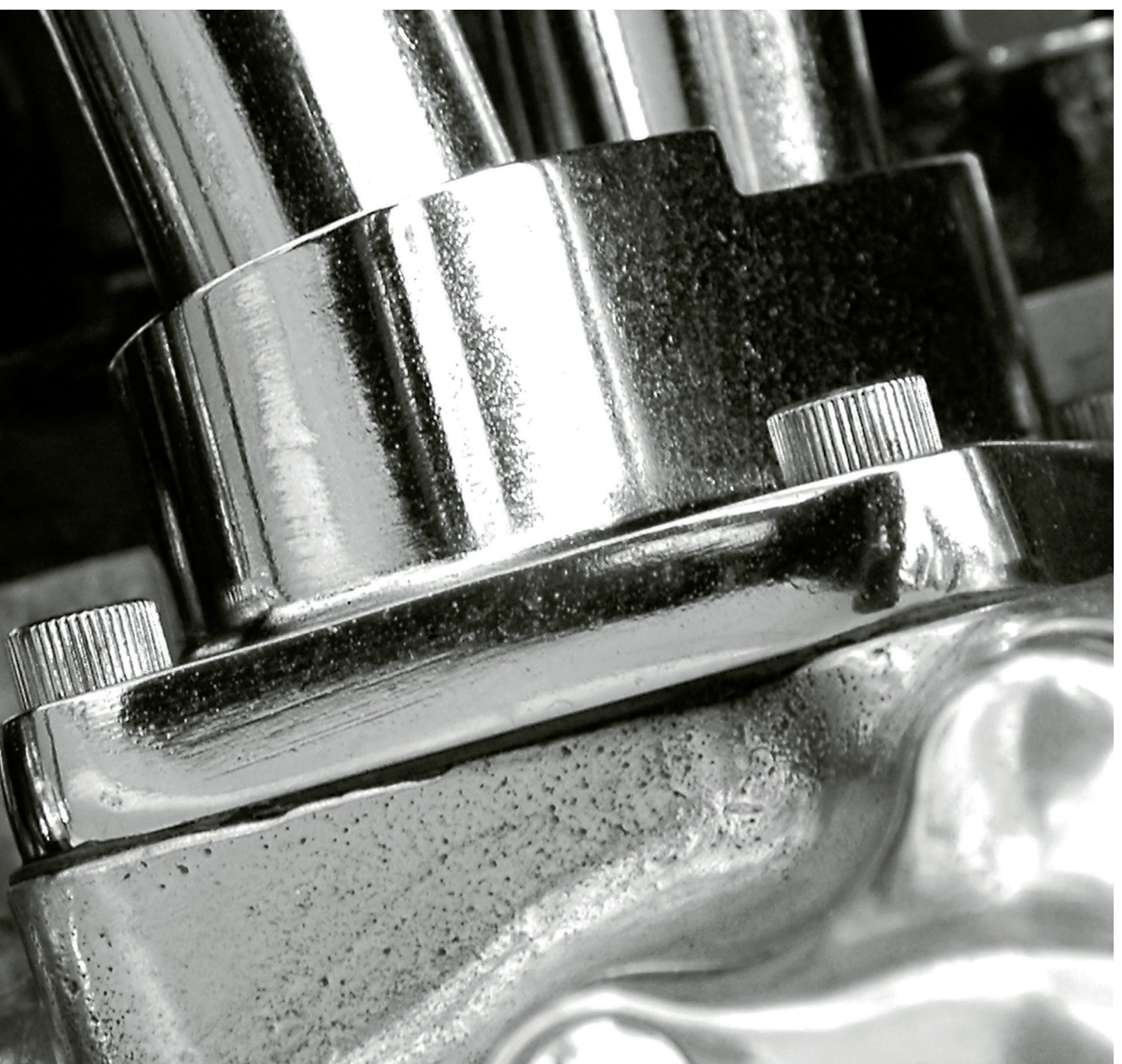

(1)
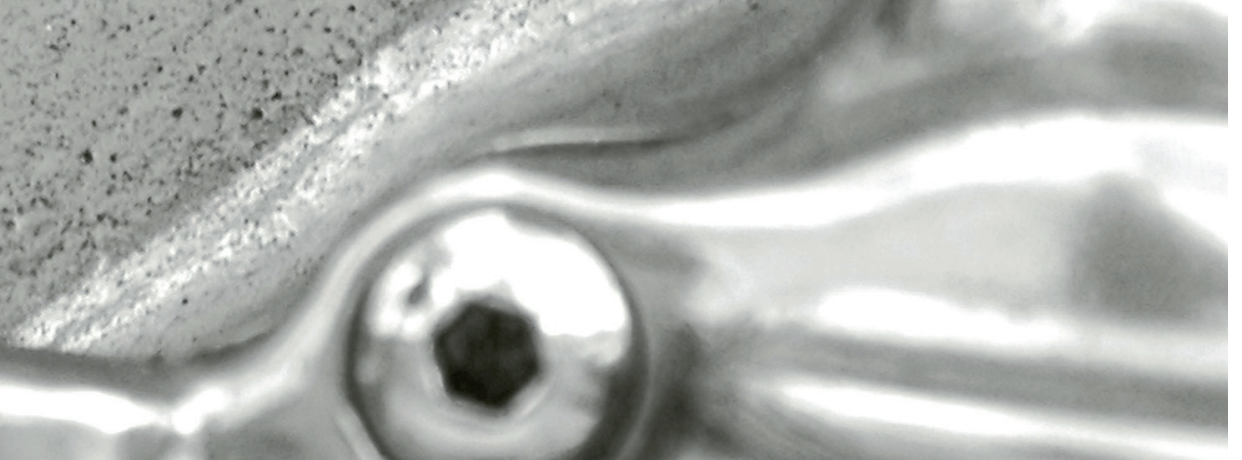